\title{
COVIMOS: A Coastal Video Monitoring System
}

\section{Made Oka Widyantara ${ }^{1}$, I Made Dwi Asana Putra ${ }^{2}$, and Ida Bagus Putu Adnyana ${ }^{3}$}

\author{
${ }^{1}$ Electrical and Computer Engineering Department, Engineering Faculty \\ Udayana University, Kampus Bukit Jimbaran \\ Badung, Indonesia 80361 \\ E-mail : oka.widyantara@unud.ac.id \\ ${ }^{2}$ Magister Electrical Engineering, Postgraduate Program, Udayana University \\ Denpasar, 80232 \\ E-mail : putraasana.09@gmail.com \\ ${ }^{3}$ Civil Engineering Department, Engineering Faculty \\ Udayana University, Kampus Bukit Jimbaran \\ Badung, Indonesia 80361 \\ E-mail : bagusadnyana32@gmail.com
}

\begin{abstract}
This paper intends to explain the development of Coastal Video Monitoring System (CoViMoS) with the main characteristics including low-cost and easy implementation. CoViMoS characteristics have been realized using the device IP camera for video image acquisition, and development of software applications with the main features including detection of shoreline and it changes are automatically. This capability was based on segmentation and classification techniques based on data mining. Detection of shoreline is done by segmenting a video image of the beach, to get a cluster of objects, namely land, sea and sky, using Self Organizing Map (SOM) algorithms. The mechanism of classification is done using K-Nearest Neighbor (K-NN) algorithms to provide the class labels to objects that have been generated on the segmentation process. Furthermore, the classification of land used as a reference object in the detection of costline. Implementation CoViMoS system for monitoring systems in Cucukan Beach, Gianyar regency, have shown that the developed system is able to detect the shoreline and its changes automatically.
\end{abstract}

Index Terms - CoViMoS, Video Monitoring, Shoreline, SOM, K-NN, IP Camera, Cucukan Beach

\section{INTRODUCTION}

One of the key elements for integrated coastal zone management is a correct understanding of the evolution of the coastal zone. However, evaluation of permanent changes in coastal morphology is not an easy task. Shoreline changes constantly due to the movement of sediment along the coast, and the dynamic nature of the surface of the water. The dynamic changes of the shoreline could have an impact on coastal erosion and increase body weight beach. This can damage the coastal environment. Therefore, monitoring of the shoreline position is very urgent activities to do, considering the socio-economic and high population density in coastal areas [1].

Shoreline monitoring system has traditionally relied on insitu measurements of waves, currents, sediment transport and morphological changes. This technique provides high quality data, but it has limitations on the resolution in space and time, because of the cost and logistical difficulties at the time of deployment. Remote sensing techniques using satellites or aircraft capable of increasing the spatial coverage of measurements with a reasonable resolution. However, the use of this technique is not cost-effective for long-term goals. Alternative techniques that may be used is a remote sensing system using video cameras. The development of multimedia and network technology on the video camera causes the price of these devices becomes very affordable. Support IP networking technology into a camera device makes it possible to build a networked video cameras in an attempt to extend the spatial coverage area to be monitored.

Application of the video system to study the coastal zone begins at the Coastal Imaging Lab., University of Oregon in the 1980s, and in 1992, called the Argus system installed at Agate Beach [2], [3]. Following the development of Argus, several similar video monitoring systems have emerged, such as Costa [4], Beachkeeper [5], SOCIB [6], and SIRENA 
[7]. features that can be used by the management of coastal

Video surveillance systems for the coastal zone has

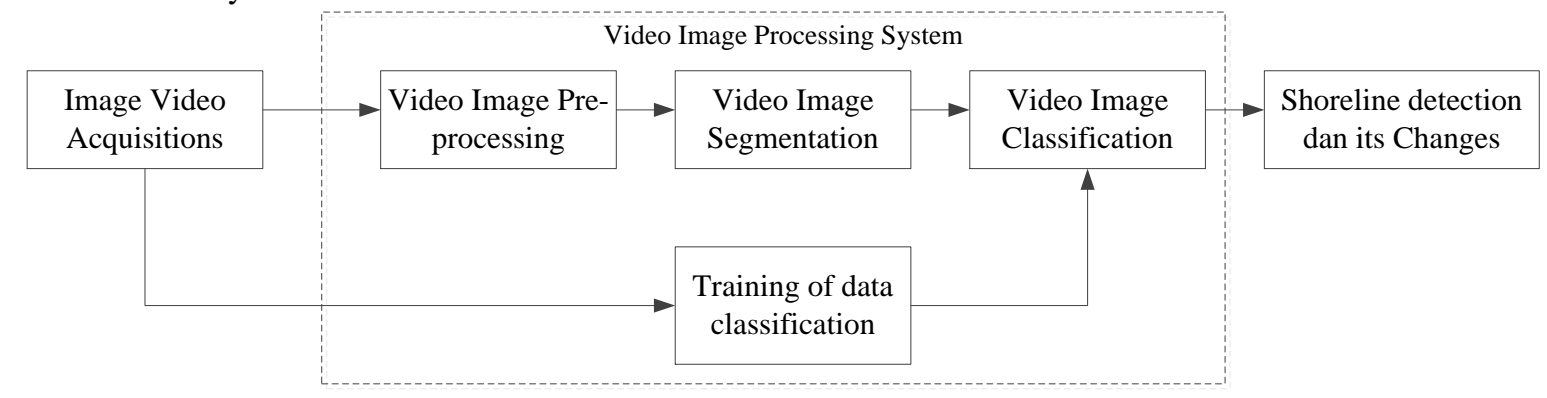

Fig. 1. The main module of the CoViMoS system

managers and scientists to manage coastal communities wisely. However, the application of video systems constrained by operational and financial factors, such as the installation of systems that require the availability of adequate electric power infrastructure [8].

Based on this background, the research has focused on developing a new video monitoring system for the detection of shoreline that is able to overcome the problems of cost and operational constraints. Coastal Video Monitoring System (CoViMoS) is a video system developed for the detection of the shoreline and its changes. CoViMoS constructed by utilizing the devices low cost video camera, and can be powered from battery or solar panel. The ability to detect the shoreline and its changes, were based on segmentation and classification techniques based on data mining. By building a reliable training method, the detection mechanism shoreline can be done automatically.

Furthermore, this paper is organized as follows: Section II describes the general description of CoViMoS, Chapter III described the implementation of CoViMoS, Chapter IV explained the results and discussion, and closed with conclusions in Chapter V.

\section{COVIMOS OVERVIEW}

CoViMoS designed to detect the shoreline and updates automatically. Systems built with the primary consideration is the low cost and easy to install. To achieve this goal, CoViMoS development strategy are:

- Using IP-based video camera devices and low-cost. Video imagery produced by these devices have limited contrast levels. So, at this stage of prepocessing, video image contrast level should be improved so as to facilitate the segmentation process.

- Perform image processing based on data mining techniques. The aim is to detect the shoreline with the segmentation and classification mechanisms.

- Detection of shoreline change is done automatically based on the data detection shoreline in the current video frame compared with the reference video frame.

- Display applications easier to use.

As shown in Fig. 1, the system CoViMoS developed in two main modules, namely video image processing system, and a detection system shoreline change

\section{A. Image Video Acquisitions}

Video image acquired from an IP camera device that is attached to a location with a certain height in order to monitor the beach area. Often the location there was no road infrastructure and electricity. This condition can be overcome by utilizing the video recording feature automatically from the IP camera. In general, IP camera device works as a simple web server, so it can be accessed directly without using an intermediary device (middleware). Images captured can be sent directly to a computer via a TCP / IP network. In CoViMoS system, video image data files stored on the computer. Furthermore, this file is processed for the purpose of detection of coastline, and to the formation mechanism of training data.

\section{B. $\quad$ Image Processing Systems}

Image processing system is a process of object recognition in image of the beach. Shoreline detection process requires a mechanism to distinguish between sea and land area. Based on data mining, recognition areas on the coast image was done by using segmentation and classification, as well as the pre-processing procedures to prepare the beach image to be processed.

\section{Image Pre-Processing}

The video frames generated by the IP camera is a color image with sunlight effect compositions that vary according to the time of acquisition. The composition of sunlight varies in coastal areas becomes a problem when separating the object on the segmentation process [9]. Therefore, it needs a repair mechanisms to improve the image display quality of video frames prior to the segmentation process. Image enhancement techniques are applied to build CoViMoS are:

\section{- Contrast Stretching Techniques}

Contrast stretching is including image enhancement process that is point processing. This means that the process is only dependent on the intensity values (gray level) one pixel, independent of other pixels in the surrounding areas. In contrast stretching, each pixel in the image transformed with [10]: 


$$
o(i, j)=\frac{u(i, j) \quad c}{d \quad c}\left(\begin{array}{ll}
L & 1
\end{array}\right)
$$

where, $o(i, j)$ and $u(i, j)$ is a pixel after and before transformed in the coordinate $(i, j)$, whereas $c$ and $d$ are the minimum and maximum values of pixels on the input image, and $L$ states the maximum grayscale value. When the pixel value is less than 0 then it will be 0 , and when greater than $(L-1)$ will be used $(L-1)$.

\section{- Morphological contrast enhancement Techniques}

The purpose of the application of morphological ontrast enhancement technique is to clarify the objects in the video image. This technique can overcome the influence of sunlight (illumination), so as to help improve the quality of image segmentation. Morphological operations performed by extracting the bright areas and dark areas. Video image with a contrast value of the newly acquired by combining extraction bright areas and dark areas in the image of the original video [9].

\section{Image Segmentations}

Video image segmentation is intended to change the image representation into a simpler form, so it is easy to analyze. Detection of shoreline require information such as the introduction of an area associated with the objects that land, sea and sky. For this purpose, CoViMoS using the technique of Self Organizing Map (SOM) as a method of segmentation. In general, SOM technique separates the objects based on similar features in the color pixels, namely by taking color index red $(R)$, green $(G)$ and Blue $(B)$ of the video image. Furthermore, SOM segmentation by seeking closeness color index of the pixel to the center of the cluster. The main characteristics of the algorithm SOM are [11]:

- Output nodes are competing for the best value, measured by the Euclidean distance (d). Output node that has the smallest distance $(d)$ between the input $(x)$ and the weight $(w)$ will be declared the winner:

$$
d(w, x)=\|w-x\|^{2}=\sqrt{\sum_{i=1}^{n}\left(w_{i}-x_{i}\right)^{2}}
$$

- Node winners will be the centerpiece of the update weights to the surrounding nodes. Thus, all the neighboring nodes of node winners will participate in the process of updating the weights.

- Updates node weights is done by using Eq. (3). In this way, each node neighbors have the chance to become the best node.

$$
w_{j i}(\text { new })=w_{j i}(\text { old })+\eta\left(x_{i}-w_{j i}(\text { old })\right)
$$

\section{Image Classifications}

Classification is a process to assess the data objects to be included in a particular class of the number of classes available. In CoViMoS, segmentation of objects in the image of the beach then analyzed for inclusion in a class of land, sea or sky, using K-Nearest Neighbor algorithm (K-NN). In general, K-NN algorithms perform classification based on proximity (distance) of an object data with others. Proximity in question is the value of closeness/similarity between the test data with training data. Rated $\mathrm{K}$ on K-NN is a K-nearest the data from the test data. KNN prediction, shown in Algorithm 1 [12].
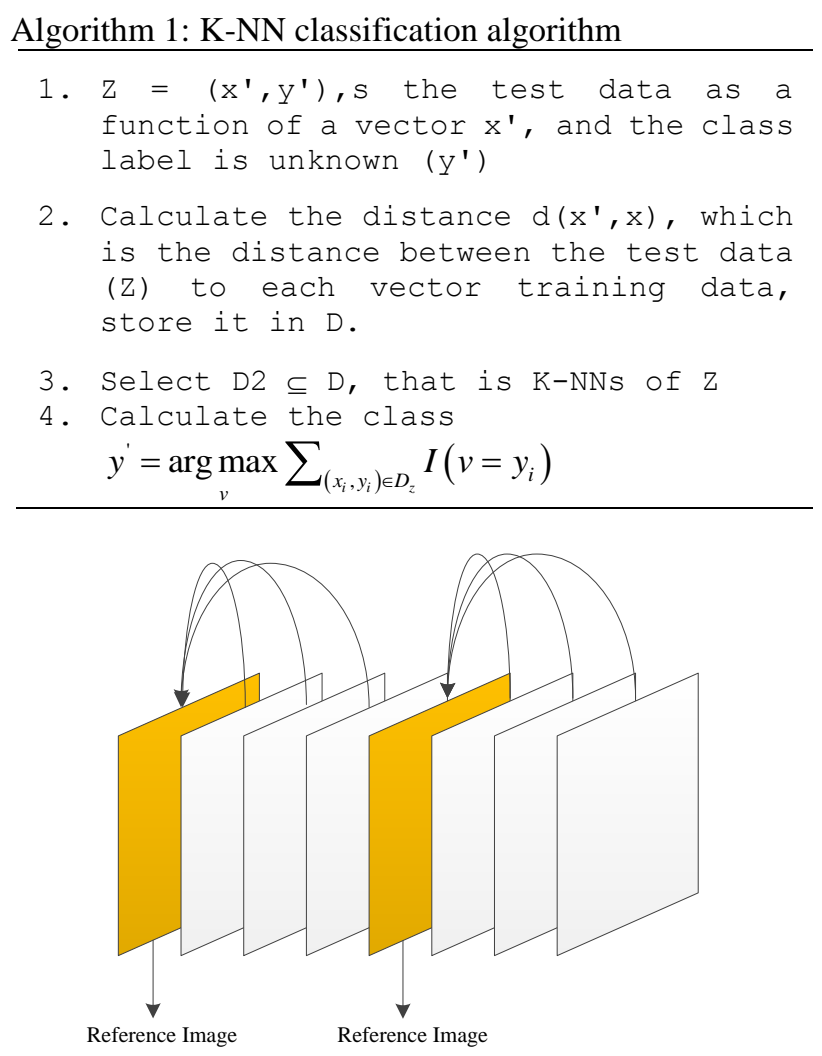

Fig. 2. GOP structure in determining shoreline change

As shown in Fig. 1, the training data on CoViMoS obtained by performing the following mechanisms:

- Input video image and label class.

- Perform image enhancement using contrast stretching operation.

- Transform the video frames from RGB to grayscale.

- Feature extraction includes entropy, energy, contrast, and homogeneity.

- Store training data on the set of training data

\section{Detection of Shoreline and Its Changes}

Determination of shoreline on CoViMoS is done after the process of classification of the beach area. Classification grouping pixels in the class label that is land, sea, not both. System looks for pixels on the label of the sea adjacent to the pixels labeled land. If the neighboring pixels are pixels with land label, then the pixel is expressed as the shoreline. The reading is done for all pixels that have the label of the sea, so that the pixels have been declared as the shoreline will form a line. Pixels are then given a color to form a shoreline.

Mechanisms for determining shoreline change is done by 

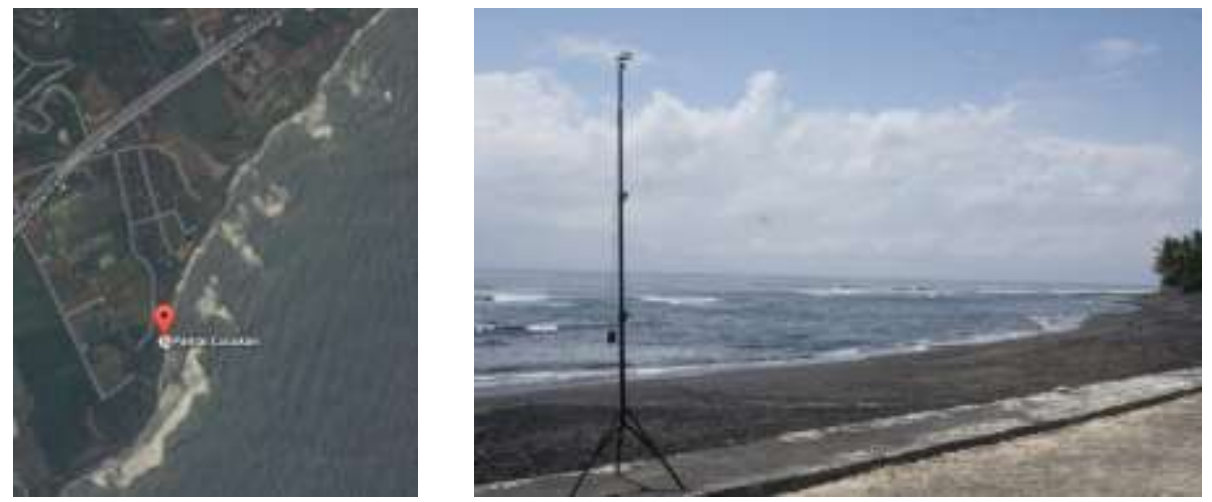

Fig. 3. Test Location Of CoViMos System, And Setting The Position Of The Camera For Image Acquisition

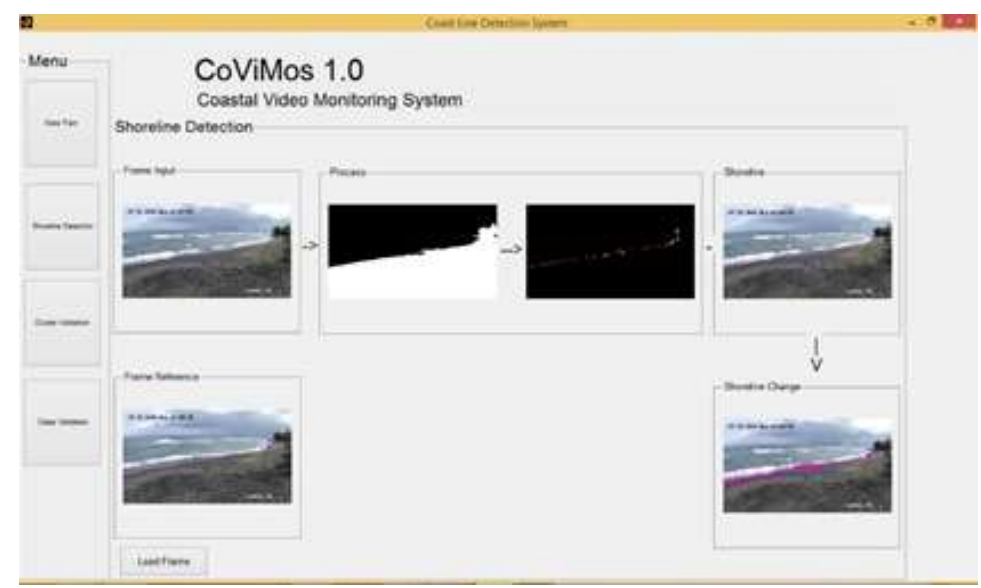

Fig. 4. Graphical User Interface CoViMoS

TABLE I

IP CAMERA SPECIFICATIONS

\begin{tabular}{cc}
\hline \hline Merk/Tipe & HIKVISION/DS-2CD2020F-IW \\
Frame rate & $30 \mathrm{fps}$ \\
Resolution & $1920 \times 1080$ \\
Video compression & H.264/ MJPEG \\
Video bit rate & $32 \mathrm{Kbps}-16 \mathrm{Mbps}$ \\
\hline \hline
\end{tabular}

exploiting the temporal correlation in video sequences. In general, an image in video sequences have a strong correlation [13], [14]. Meanwhile, the characteristics of the video image of the beach has a movement of an object focused on the dynamics of the sea and land meeting. With this assumption, the coastline changes can be seen by comparing two video images is already known position of its shoreline. In CoViMoS system, determination of shoreline change were conducted using a reference image on a Group of Pictures (GOP). Fig. 2 shows the GOP structure is used.

\section{SYSTEM IMPLEMENTATIONS}

CoViMoS prototype has been implemented to monitor Cucukan beach. As shown in Fig. 3, this beach is located in the village Cucukan, Gianyar, Bali, Indonesia. The focus of the application is testing this capability CoViMoS system in determining the position of the coastline and its amendments. Table 1 shows the specifications of IP cameras used for image acquisition.

In CoViMoS system testing, there are several test conditions used, namely:

- The acquisition of images taken by IP cameras at a height of 4 meters from the surface of the beach.

- Imagery processed by the system CoViMoS extracted from .mp4 video file into samples of images in .jpeg format.

- Shoreline change detection procedure using a GOP size 4.

- Feature extraction for segmentation process performed on the criteria of the RGB color components.

- SOM segmentation algorithm was set on some attribute value, i.e., the learning rate is 0.5 , the learning function is 0.2 , and the initialization of the initial weight is randomly determined according to the number of clusters.

\section{RESUlTS AND DISCUSSIONS}

\section{A. Evaluation of Performance Detection Shorelines}

As shown in Fig. 4, CoViMoS application has several modules, namely, the detection of shoreline changes, the training of data classification, and segmentation and classification validation. These modules can be used as the 

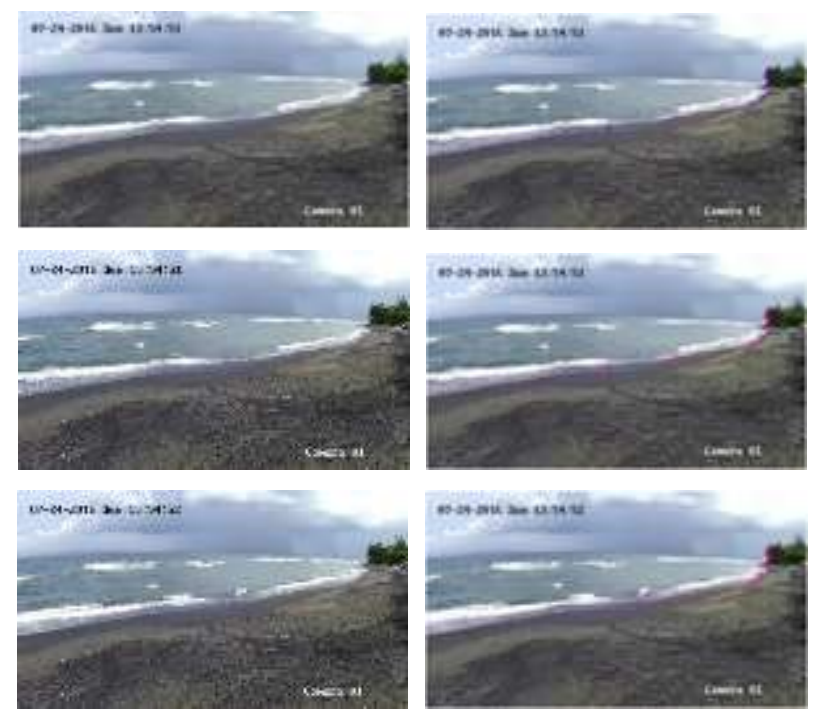

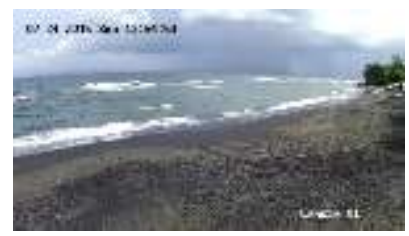

(a)

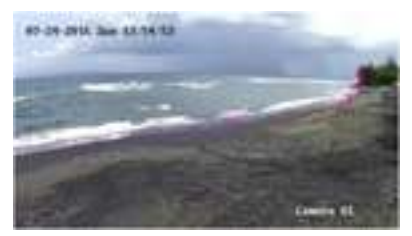

(b)

Fig. 5. Monitoring Cucukan shoreline, (a) input image, (b) detection results shoreline

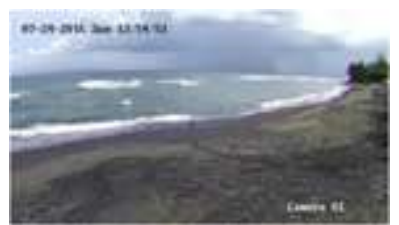

(a)

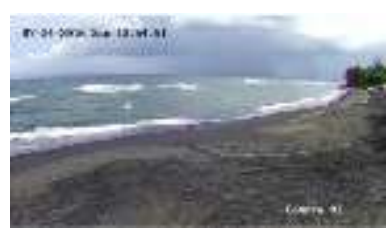

(b)

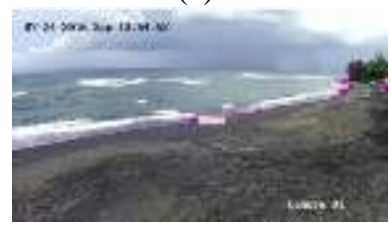

(c)

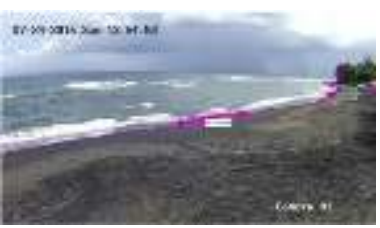

(d)

Fig. 6. Cucukan shoreline change detection, (a) the reference image, (b) Sample image 2, (c) Sample image 3, and (d) Sample image 4

basis for the development of CoViMoS performance analysis to detect changes in the shoreline.

As shown in Figure 5, in general, the CoViMoS is able to detect the position of Cucukan shoreline. This indicates that SOM is able to segment the object either land, sea and sky in the image Cucukan Beach. The good performance of the segmentation process is also supported by the implementation of Contrast Stretching techniques combined with Morphological Contrast Enhancement techniques in the image enhancement process. Implementation of the techniques prepocessing also able to improve the contrast of objects in the image of the beach, so the object land, sea and sky in the image of the beach can be clearly exposed. K-NN classification process is also able to put the right class for objects land. As shown in Figure 5, in the gray level image format, $\mathrm{K}-\mathrm{NN}$ algorithm is able to detect onshore areas drawing a line end to end of the respective coastlines. It (white colored object). The edge of the land object is then set as the position of the shoreline.

\section{B. Performance Evaluation of the detection of changes Shoreline}

The process of determining the area of shoreline change is done by finding the difference between the land area in the reference frame with the input frame. Fig. 6 has shown the results of detection of shoreline change in the structure of GOP size 4. In this case, the video image of the first sequence is used as a reference frame for the next three video image. A reference image and the input image is already known position of its shoreline is overlaid in order to obtain two different lines. A blue line is the shoreline in the reference video image, and the red line is the shoreline in the input video image. Shoreline change is measured by

covered the area that changes is measured in pixels. As 
shown in Fig. 6, the CoViMoS system is able to detect changes of Cucukan shoreline. Detection results also showed that there was no significant change in the Cucukan shoreline.

\section{CONCLUSION}

This paper has described the development and evaluation mechanism CoViMoS to detect changes in the shoreline. CoViMoS system developed in three (3) main modules, namely video image acquisition, image processing based on data mining techniques, and detecting changes in the coastline. The simulation results showed that CoViMoS able to detect the shoreline and its changes to the video image Cucukan Beach, which is on the acquisition using the IP camera.

\section{ACKNOWLEDGMENT}

This work was funded by competitive research grants in 2016 from Udayana University under the contract number 486.25/UN14.2/PNL.01.03.00/2016.

\section{REFERENCES}

[1] C. E. Huisman, K. R. Bryan, G. Coco, and B. G. Ruessink, "The use of video imagery to analyse groundwater and shoreline dynamics on a dissipative beach," Cont. Shelf Res., vol. 31, no. 16, pp. 1728-1738, 2011.

[2] R. A. Holman, A. H. Sallenger, T. C. Lippmann, and J. W. Haines, "The application of video image processing to the study of nearshore processes," Oceanography, vol. 6, no. 3, pp. 78-85, 1993.

[3] R. A. Holman and J. Stanley, "The history and technical capabilities of Argus," Coast. Eng., vol. 54, no. 6, pp. 477-491, 2007.

[4] "kostasystem.".

[5] C. Dessy, C. F. Schiaffino, N. Corradi, and M. Ferrari, "Nourishment of Levanto (Italy): a webcam-aided evaluation of a mixed sand and gravel beach fill," BEACH Eros. Monit., p. 119, 2008.

[6] "SOCIB." [Online]. Available: http://www.socib.eu/. [Accessed: 23-Feb-2017].

[7] M. A. Nieto et al., "An open source, low cost video-based coastal monitoring system," Earth Surf. Process. Landf., vol. 35, no. 14, pp. 1712 1719, 2010.

[8] M. Davidson et al., "The CoastView project: Developing videoderived Coastal State Indicators in support of coastal zone management," Coast. Eng., vol. 54, no. 6, pp. 463-475, 2007.

[9] I Made Oka Widyantara, N.M.A.E.D. Wirastuti, I Made Dwi Putra Asana, and Ida Bagus Putu Adnyana, "Image Enhancement Using Morphological Contrast Enhancement for Video Based Image Analysis," presented at the International Conference on Data and Software Engineering (ICODSE), Denpasar.

[10] S. S. Al-amri, "Contrast Stretching Enhancement in Remote Sensing Image."

[11] T. Kohonen, "Essentials of the self-organizing map," Neural Netw., vol. 37, pp. 52-65, 2013.

[12] J. KIM\$^1\$, B.-S. Kim, and S. Savarese, "Comparing image classification methods: K-nearest-neighbor and support-vector-machines," Ann Arbor, vol. 1001, pp. 48109-2122, 2012.

[13] I Made Oka Widyantara, "Decoding Approach With Unsupervised Learning of Two Motion Fields For Improving Wyner-Ziv Coding of Video," Int. J. Appl. Eng. Res., vol. 10, no. 5, pp. 11763-11776.

[14] I. Widyantara and G. Hendrantoro, "Reducing Decoding Complexity by Improving Motion Field Using Bicubic and Lanczos Interpolation Techniques in Wyner-Ziv Video Coding.," KSII Trans. Internet Inf. Syst., vol. 6, no. 9, 2012. 